\title{
Occurrence and spatial distribution of organophosphorus flame retardants and plasticizers in the Bohai, Yellow and East China seas
}

\author{
Mingyu Zhong ${ }^{\mathrm{a}}$, Jianhui Tang ${ }^{\mathrm{b}, \mathrm{c}, *}$, Xinyu Guo ${ }^{\mathrm{d}}$, Chao Guo ${ }^{\mathrm{b}, \mathrm{e}}$, Fei Li ${ }^{\mathrm{b}}$, Huifeng $\mathrm{Wu}^{\mathrm{b}}$ \\ a Ocean School, Yantai University, Yantai 264005, China \\ b Key Laboratory of Coastal Environmental Processes and Ecological Remediation, Yantai Institute of Coastal Zone Research (YIC), Chinese Academy of Sciences, Yantai 264003, China \\ c Center for Ocean Mega-Science, Chinese Academy of Sciences, Qingdao 266071, China \\ d Center for Marine Environmental Studies, Ehime University, Matsuyama 790-8577, Japan \\ e University of Chinese Academy of Sciences, Beijing 100049, China
}

\section{H I G H L I G H T S}

- OPEs were wildly detected in the Bohai (BS), Yellow (YS), and East China Seas (ECS).

- OPE inventories were calculated in the $\mathrm{BS}$, YS, and ECS.

- Ocean currents and riverine inputs influence the horizontal distribution of OPEs.

- River input and water stratification influence the vertical distribution of OPEs.

- OPEs showed higher concentrations in winter than in summer in the BS and the YS.

\section{A R T I C L E I N F O}

\section{Article history:}

Received 14 February 2020

Received in revised form 16 June 2020

Accepted 20 June 2020

Available online 23 June 2020

Editor: Jay Gan

\section{Keywords:}

Organophosphate esters

Concentrations and distributions

Seasonal variation

Chinese marginal sea
GRAPHICALA B STRACT

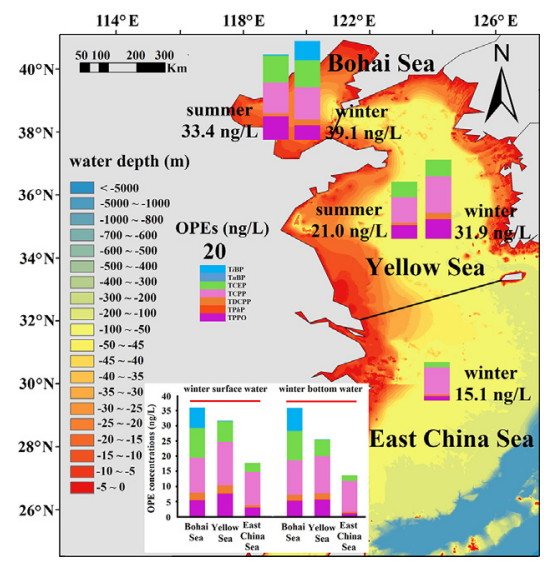

\begin{abstract}
A B S T R A C T
Organophosphate esters (OPEs) are man-made organic pollutants that are used in flame retardants (FRs), plasticizers, antifoaming and hydraulic agents, and extractants. The demand for FRs in China has increased, thereby rapidly increasing the use of OPEs and hence resulted in its high levels in the environment. In this study, we measured the concentrations of seven OPE congeners in the seawaters of the Bohai Sea (BS), the Yellow Sea (YS), and the East China Sea (ECS). The horizontal and vertical spatial distributions were then analyzed to assess the OPE pollution. The total concentrations of the seven OPE congeners ( $\Sigma O P E s)$ in the three seas ranged from 7.31 to $100 \mathrm{ng} \mathrm{L}^{-1}$. The main OPE compounds were tris-(1-chloro-2-propyl) phosphate (TCPP, 3.97-35.6 ng L ${ }^{-1}$ ), tris(2-chloroethyl) phosphate (TCEP, 0.59-19.8 $\mathrm{ng} \mathrm{L}^{-1}$ ), and triphenylphosphine oxide (TPPO, from below the detection limit to $43.5 \mathrm{ng} \mathrm{L}^{-1}$ ). The inventory of the $\mathrm{OOPEs}$ in the BS, YS, and ECS was estimated as 54.2, 513, and 3950 tons, respectively. Horizontally, the $\mathrm{ZOPE}$ concentration was ranked as BS > YS > ECS. In the vertical direction, the OPE concentrations in the surface water were higher than those in the bottom water. Ocean currents and riverine inputs might be the main factors influencing the distributions of the OPEs in these seas. Moreover, a seasonal variation (summer 2015 versus winter 2016) in the OPEs was observed in the YS, which was probably due to anthropogenic influences and hydrological, meteorological, and biological factors.
\end{abstract}

(c) 2020 Elsevier B.V. All rights reserved.

\footnotetext{
* Corresponding author at: Key Laboratory of Coastal Environmental Processes and Ecological Remediation, Yantai Institute of Coastal Zone Research (YIC), Chinese Academy of Sciences, Yantai 264003, China.

E-mail address: jhtang@yic.ac.cn (J. Tang).
} 


\section{Introduction}

Organophosphate esters (OPEs) are man-made organic pollutants with a central phosphorus atom and various substituent functional groups, according to which OPEs can be classified as alkyl, aryl, or chlorinated OPEs (Zhong et al., 2017; Zhong et al., 2018). In addition to their main used as flame retardants (FRs), OPEs can also be used as plasticizers, antifoaming and hydraulic agents, and extractants in other industries (Reemtsma et al., 2008). OPEs were replaced by other flame retardants during the 1960s and 1970s owing to their significant residual concentrations in the environment (Hao et al., 2018). However, with the phasing out of certain polybrominated diphenyl ethers (PBDEs) by the European Union's in 2004, OPEs, as flame retardants, returned to the global market as an efficient alternative to PBDEs (Hao et al., 2018). The production and use of OPEs subsequently increased significantly (Wang et al., 2015). In the western European market, the annual consumption of OPEs increased to 80,000 tons (t), which accounted for $20 \%$ of the total FR market share at that time (Rodil et al., 2005). Meanwhile, as the largest developing country and the second largest economy worldwide, China had a demand for FRs of 300,000 $t$ in 2013, after which the country's usage of OPEs increased rapidly (Zhang, 2014). Globally, approximately 500,000 t of OPEs was used in 2011, and the market demand for OPEs was previously projected to reach 680,000 t by 2015 (Ou, 2011; van der Veen and de Boer, 2012).

OPEs are a type of additive flame retardant, suggesting that they non-covalently bond to the added materials and are liable to leach into the environment (Zhong et al., 2018). These compounds, especially those that are chlorinated, are resistant to degradation after they enter into the environment; therefore, it is difficult to eliminate them from the environment. In recent years, several studies have investigated the occurrence of OPEs in air (Fromme et al., 2014; Moller et al., 2012; Staaf and Ostman, 2005), dust (Ali et al., 2012; Marklund et al., 2003; Stapleton et al., 2009; Pang et al., 2019), water (Hu et al., 2014; Wang et al., 2015; Zhong et al., 2017; Niu et al., 2019), sediment (Cao et al., 2017; Wang et al., 2017; Zhong et al., 2018; Li et al., 2019), soil (Mihajlovic et al., 2011), and biota (Chen et al., 2012; Liu et al., 2018; Ma et al., 2013). The findings of these studies implied a ubiquitous existence of OPEs in the environment. Additionally, OPEs have been detected in remote areas far from the pollution sources, including the open oceans (Li et al., 2017; Ma et al., 2017) and polar regions (Li et al., 2017; Sühring et al., 2016), which indicates their ability to undergo long-range transport (LRT). Although the toxicities of OPEs to humans have not been reported sufficiently, their carcinogenicity, neurotoxicity, teratogenicity, cytotoxicity, and metabolic toxicity to other species and human cells have been investigated in recent years, with the findings suggesting the potential risks of OPEs to human health (Greaves and Letcher, 2017; Niu et al., 2019).

The Bohai Sea (BS), Yellow Sea (YS), and East China Sea (ECS) are important marginal seas of China. These seas are adjacent to the most developed and populated regions in eastern China, and thereby receiving large volumes of domestic sewage and industrial wastewater, which significantly deteriorate the coastal water quality (Hu et al., 2011; Ma et al., 2001; Shen et al., 2013; Zhong et al., 2017). High concentrations of OPEs have been detected in the BS and YS and in rivers draining into these seas (Wang et al., 2015; Zhong et al., 2017). Meanwhile, the $\mathrm{BS}, \mathrm{YS}$, and ECS have complex hydrodynamic features, and the distributions of organic pollutants are profoundly influenced by ocean currents. These currents include the Bohai Sea Coastal Current (BSCC), Subei Coastal Current, Changjiang Diluted Water (CDW), Zhejiang Fujian Coastal Current (ZFCC), Taiwan Warm Current (TaWC), and Yellow Sea Warm Current (YSWC) (Liu et al., 2007; Zhong et al., 2017). However, the concentrations and distributions of OPEs in the seawater of the ECS and the seasonal variations (summer v.s. winter) of OPEs in the seawater of the BS and YS have not yet been systematically studied and discussed. Accordingly, this study collected and analyzed seawater samples from 61 sites in the BS, YS, and ECS to (i) investigate the concentrations, compositions, and distributions of 7 OPEs congeners [tris-(2-chloroethyl) phosphate (TCEP), tris-(1-chloro-2-propyl) phosphate (TCPP), tris-(1,3-dichloro-2-propyl) phosphate (TDCPP), triisobutyl phosphate (TiBP), tri-n-butyl phosphate (TnBP), triphenyl phosphate (TPhP), and triphenylphosphine oxide (TPPO)]; (ii) explore the factors that may influence the spatial distributions of these OPEs; and (iii) discuss the seasonal variations of these OPEs in the BS and YS.

\section{Materials and methods}

\subsection{Sampling cruise}

From November 10 to December 24, 2016 (i.e. winter), 177 seawater samples from 61 sites in the Bohai Sea, Yellow Sea, and East China Sea were collected during a cruise on the research vessel (Beidou) for the analysis of OPE congeners (Table S1). The locations of the sampling sites are shown in Fig. 1 and are listed in Table S2. To reveal the vertical variations of the seven OPEs, we collected seawater samples from the surface and bottom layers in shallow water regions and from up to six layers in deep water regions (Table S2). An automated conductivitytemperature-depth system (CTD) sampling device (Seabird 25, USA) equipped with Niskin bottles was used to collect the seawater samples from the different layers.

\subsection{Chemicals}

All the organic solvents used in this study were of chromatographic grade and were purchased from Merck (Germany). Information concerning the analytical standards is provided in Table S1.

\subsection{Sample pretreatment}

The pretreatment process followed the procedure proposed by Zhong et al. (2017) with minor modifications. In detail, 20 ng each of surrogates ( $\mathrm{D}_{27}-\mathrm{T} n \mathrm{BP}, \mathrm{D}_{12}-\mathrm{TCEP}$, and $\left.\mathrm{D}_{15}-\mathrm{TP} h \mathrm{P}\right)$ was added to $1 \mathrm{~L}$ seawater (for each sample), which was then filtered through a glass microfiber filter (pore size: $0.7 \mu \mathrm{m}$; Whatman, UK). The filtered sample was immediately transferred to a pretreated separating funnel and passed through an OASIS hydrophilic - lipophilic balance (HLB) cartridge $\left(6 \mathrm{~cm}^{3}, 200 \mathrm{mg}\right.$; Waters) on board the R/V. The HLB cartridge was pretreated by adding $6 \mathrm{~mL}$ of ethyl acetate and $6 \mathrm{~mL}$ of methanol. Then, it was sealed with cleaned foil and stored at $-20{ }^{\circ} \mathrm{C}$. Subsequently, the loaded HLB column was drained and eluted with $10 \mathrm{~mL}$ of ethyl acetate using solid phase extraction. Then, the eluent was frozen overnight (at least $12 \mathrm{~h}$ ) at $-20^{\circ} \mathrm{C}$ to remove water. The residual water was removed again by adding $3 \mathrm{~g}$ of baked sodium sulfate. Then, the eluent was transferred to a new vial and evaporated to a volume of $200 \mu \mathrm{L}$ under a gentle nitrogen flow. Finally, $20 \mathrm{ng}$ of polychlorinated biphenyl 208 (PCB 208) was added before instrumental analysis as an injection standard (see the Supporting Information).

\subsection{Instrumental analysis}

A gas chromatograph (Agilent 6890) coupled with a mass spectrometer (Agilent 5973) was employed to analyze all the pretreated samples, as described by Zhong et al. (2017). Details of the analysis processes are provided in the Supporting Information.

\subsection{Quality assurance and quality control}

Both blank and spiked experiments were conducted to evaluate the method blanks and recoveries, respectively. For the blank experiment, $40 \mathrm{ng}$ each of surrogates $\left(\mathrm{D}_{27}-\mathrm{TnBP}, \mathrm{D}_{12}-\mathrm{TCEP}\right.$, and $\left.\mathrm{D}_{15}-\mathrm{TPhP}\right)$ was added to $1 \mathrm{~L}$ of the ultra-pure water. For the spiked experiment, $40 \mathrm{ng}$ each of surrogates $\left(\mathrm{D}_{27}-\mathrm{T} n \mathrm{BP}, \mathrm{D}_{12}\right.$-TCEP, and $\left.\mathrm{D}_{15}-\mathrm{TP} h \mathrm{P}\right)$ and $100 \mathrm{ng}$ of the seven OPE congeners were added to $1 \mathrm{~L}$ of the ultra-pure water. 


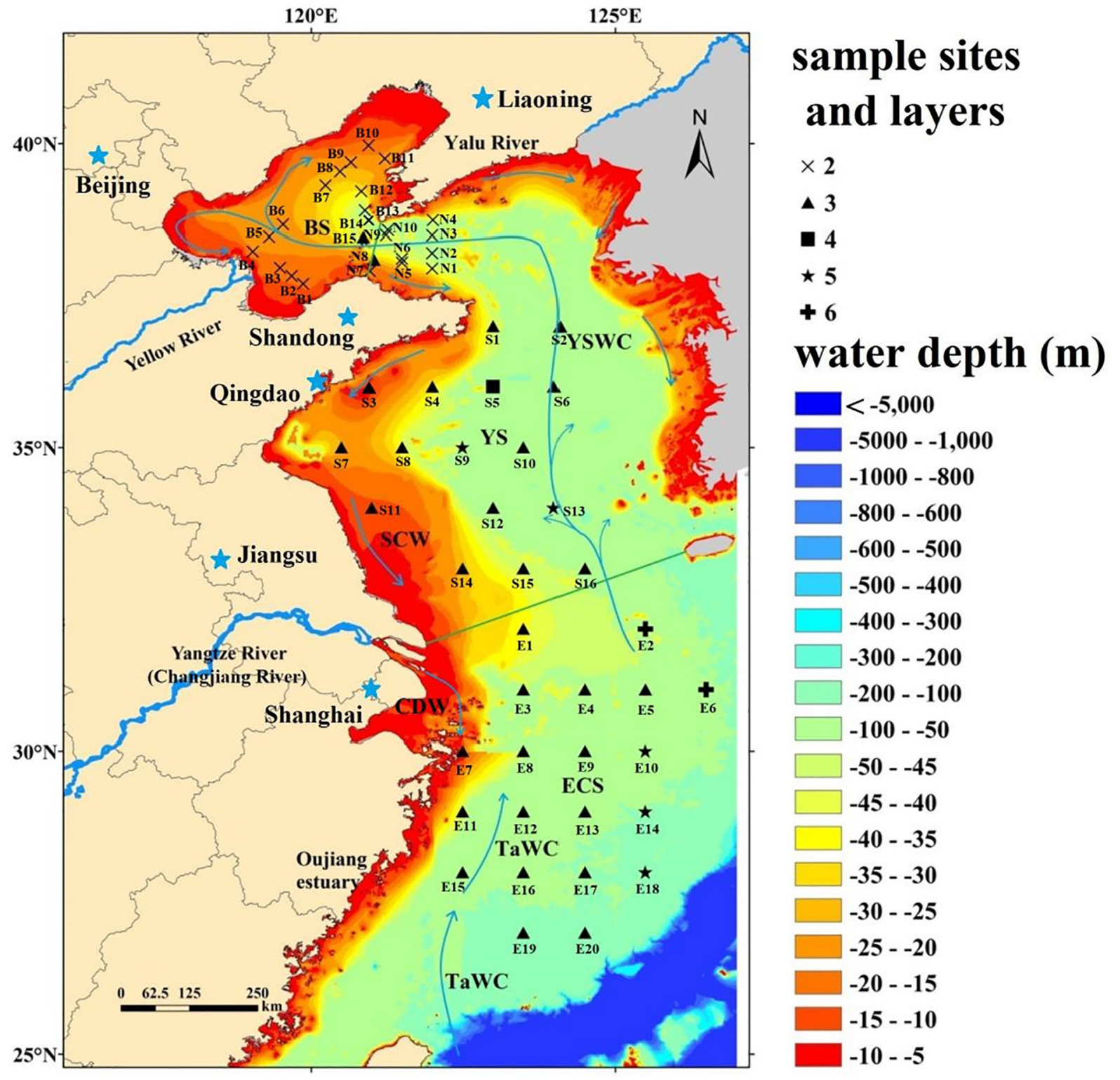

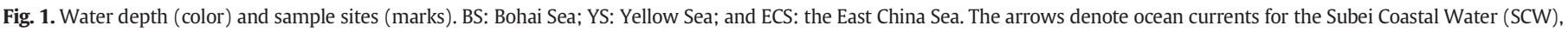

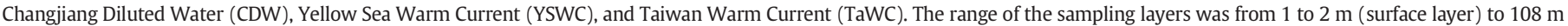
(bottom layer), with detailed information provided in Table S2 of the Supporting Information.

For both the blank and spiked experiments, $32 \mathrm{~g}$ of sodium chloride was added to the ultra-pure water for simulating the salinity of the seawater. The remaining procedures were similar to those of the sample pretreatment.

The concentrations of the method blanks ranged from $30 \pm 25$ ( $\mathrm{T} n \mathrm{BP})$ to $433 \pm 22 \mathrm{pg} \mathrm{L}^{-1}$ (TPPO) $(n=6)$, whereas the method recoveries ranged from $88 \% \pm 2 \%(\mathrm{TP} h \mathrm{P})$ to $107 \% \pm 8 \%(\mathrm{~T} n \mathrm{BP})(n=6)$. The method detection limit (MDL) was defined as the method blanks plus three times the standard deviation $(3 \sigma)$ of the method blanks and ranged from 82 (TPhP) to $529 \mathrm{pg} \mathrm{L}^{-1}$ (TPPO). Detailed information regarding the blanks, recoveries, MDL, and limit of instrumental detection (LOD) (calculated at a signal-to-noise ratio of 3) are listed in Table S1.

\subsection{Statistical analysis}

The OPE concentration data were extracted by Chemstation Data Analysis software and further processed using Excel 2017. A significance analysis between the data was performed using SPSS 19.0 one-way analysis of variance (ANOVA) and paired sample $t$-test. The distributions of the OPE concentrations were plotted using ArcGIS 10.0.

\section{Results and discussion}

\subsection{OPE concentrations}

Overall, five of the seven OPEs (TCEP, TCPP, TDCPP, TPhP, and TPPO) were detected in the seawaters of the Bohai Sea, Yellow Sea, and East China Sea, whereas the remaining two OPEs (TiBP and TnBP) were only sporadically detected in the BS and YS. The concentration data for the seven OPEs are listed in Table S2 and summarized in Table 1. As shown in Table 1, the total concentrations of the seven OPEs ( $\Sigma O P E s$ ) in all three seas ranged from 8.81 to $100 \mathrm{ng} \mathrm{L}^{-1}$, with a geometric mean concentration (GM) of $24.0 \mathrm{ng} \mathrm{L}^{-1}$. The $\Sigma \mathrm{OPE}$ concentrations ranged from 19.7 to $100 \mathrm{ng} \mathrm{L}^{-1}$ ( $\mathrm{GM}$ of $39.1 \mathrm{ng} \mathrm{L}^{-1}$ ) in the Bohai Sea, 
9.26 to $86.8 \mathrm{ng} \mathrm{L}^{-1}$ (GM of $30.7 \mathrm{ng} \mathrm{L}^{-1}$ ) in the Yellow Sea, and 8.81 to $55.7 \mathrm{ng} \mathrm{L}^{-1}$ ( $\mathrm{GM}$ of $15.1 \mathrm{ng} \mathrm{L}^{-1}$ ) in the East China Sea.

Of the individual OPEs, the chlorinated OPEs (i.e., TCEP, TCPP, and TDCPP) and TPPO were the main OPE compounds, whereas alkyl and aryl congeners only accounted for a small proportion of the total. As shown in Table 1, the concentrations of TCEP and TCPP ranged from 0.59 to $19.8 \mathrm{ng} \mathrm{L}^{-1}$ (GM of $4.04 \mathrm{ng} \mathrm{L}^{-1}$ ) and from 3.97 to $35.6 \mathrm{ng} \mathrm{L}^{-1}$ (GM of $11.3 \mathrm{ng} \mathrm{L}^{-1}$ ), respectively, with $100 \%$ detection rates for both. As another chlorinated OPE, the concentration of TDCPP (from $<$ MDL to $8.13 \mathrm{ng} \mathrm{L}^{-1}$; GM of $\left.1.16 \mathrm{ng} \mathrm{L}^{-1}\right)$ was significantly lower $(P<0.01)$ than the concentrations of the TCEP and TCPP. Meanwhile, the detection rate of TDCPP was $89 \%$, which was also lower than that of the TCEP and TCPP. The concentration of TPPO ranged from $<$ MDL to $43.5 \mathrm{ng} \mathrm{L}^{-1}$, with a detection rate of $\sim 100 \%$. With respect to the two alkyl OPEs, the concentrations of TiBP ranged from $<$ MDL to $27.4 \mathrm{ng} \mathrm{L}^{-1}$ (GM of $0.166 \mathrm{ng} \mathrm{L}^{-1}$ ), whereas that of TnBP ranged from $<$ MDL to $37.2 \mathrm{ng} \mathrm{L}^{-1}$ (GM of $<\mathrm{MDL}$ ). The detection rates of TiBP and $\mathrm{T} n \mathrm{BP}$ only reached $24 \%$ and $5 \%$, respectively.

\subsection{Calculation of the OPE inventories}

As OPEs were frequently detected in the seawater of the Bohai Sea, Yellow Sea and East China Sea, the inventories of the $\Sigma O P E s$ and individual OPEs in these areas were calculated using the method proposed by Cao et al. (2017). The average water depth of the BS, YS, and ECS is 18, 44 , and $340 \mathrm{~m}$, respectively, with each covering an approximate area of $7.70 \times 10^{4}, 3.80 \times 10^{5}$, and $7.7 \times 10^{5} \mathrm{~km}^{2}$, respectively. The estimated volume of seawater in the BS, YS, and ECS is $1.386 \times 10^{12}, 1.672 \times 10^{13}$, and $2.618 \times 10^{14} \mathrm{~m}^{3}$, respectively. By multiplying the volume of seawater with the geometric mean concentrations of the $\Sigma$ OPEs and individual OPEs (Section 3.1 and Table 1) in each sea, the inventory of the OPEs in each region was determined (Table 2). The inventory of the $\Sigma$ OPEs ranged from $54.2 \mathrm{t}$ from the BS to $3953 \mathrm{t}$ for the ECS, and TCPP in the ECS was the most abundant individual OPE.

According to Ou (2011), the phasing out of BFRs in China led to a demand gap between $1.5 \times 10^{5}$ and $2.0 \times 10^{5} \mathrm{t}$ in non-brominated flame retardant such as OPEs, and the annual consumption growth of OPEs was expected to reach $15 \%$. Compared with the usage of OPEs in China, input of the OPEs into the three marginal seas still only accounted for a relatively small proportion. This suggested that the OPEs had not entirely leached out from the added materials and/or that a considerable proportion of the OPEs had not yet entered the marine environment.

\subsection{Spatial distributions of the OPES}

\subsubsection{Horizontal distribution of the OPES}

Fig. 2 shows that the Bohai Sea exhibited the highest $\Sigma O P E$ concentrations, followed by the Yellow Sea and East China Sea. The horizontal distributions of TiBP and TCEP concentrations followed the pattern of the $\Sigma O P E$ concentrations. This can be explained by the fact that there are more pollution sources around the Bohai Sea than those around the Yellow Sea and the East China Sea, as well as the poorer water exchange in the Bohai Sea than that in the Yellow Sea and East China Sea, which are closer to the western Pacific Ocean) (Zhong et al., 2017). Meanwhile, TnBP was only detected at one site (B3) in the Bohai Sea and sparsely detected at several sites in the Yellow Sea. This phenomenon might be attributed to the limited sources of this OPE in the Bohai Sea and the Yellow Sea and its high degradability as an alkyl OPE (Regnery and Puttmann, 2010). Interestingly, the distribution of $\mathrm{T} n \mathrm{BP}$ in the N1-N4 section showed an obvious decreasing trend from the south (Shandong Province) to the north (Liaoning Province), which implies limited sources of TnBP in the Shandong Province.

The concentrations of TCPP, TDCPP, and TPPO exhibited different distribution patterns than those of the $\mathrm{EOPEs}$ (Fig. 2). These three compounds presented higher concentrations in the Yellow Sea than in the
Bohai Sea and the East China Sea, which suggests that there was a higher input of these OPEs in the Yellow Sea. In fact, one of the largest OPE manufacturers in China is located on the west coast of the southern Yellow Sea, with an annual OPE production of 20,000 $t$ and TCPP and TDCPP being their dominant products. Meanwhile, dozens of pharmaceutical companies are also situated in Jiangsu Province, and they use TPPO as intermediates for producing medicines. Thus, waste water from these companies could be regarded as an exclusive TPPO source to the Yellow Sea (Wang et al., 2015; Zhong et al., 2017). Interestingly, on the S11-S13 transect (Fig. 2), the concentrations of several individual OPEs (TDCPP, TCPP, and TPPO) and the $\Sigma$ OPEs were also higher at the sites adjacent to the Korean Peninsula side in comparison to sites in the middle of the transect. This pattern indicates that there might also be OPE sources on the Korean Peninsula, and that the OPEs from these sources were transported to site S13. This hypothesis was partially supported by the surface currents, as shown in Fig. S1 in the Supporting Information. Nevertheless, with the ascending trends of salinity among the transects (E1E2, E3-E6, E7-E10, E11-E14, E15-E18 and E19-E20), the distribution of the OPEs in the East China Sea agreed well with the descending trend from the nearshore to the offshore regions, which is a typical pattern for land sourced pollutants. However, site E16 on the E15-E18 transect had higher OPE concentrations than those of the nearshore E15 site. Meanwhile, relatively high OPE concentrations were found at the Oujiang estuary (OE) site, which also suggests a terrigenous origin of OPEs in the E15-E18 transect. Thus, it can be argued that this phenomenon may be due to the dilution of the OPE concentration at site E15 by the Taiwan Warm Current (TaWC, Fig. 1), which originates from a branch of the Kuroshio Current along with seawater inputs from the southeast of Taiwan (Wei et al., 2016; Zhong et al., 2017).

\subsubsection{Vertical distribution of the OPES}

The vertical distribution of the seven OPEs in the three seas was also obtained. As shown in Table S3, in comparison with the concentrations in deeper layers, the surface water was characterized by a higher concentration of $\triangle O P E, T C E P$, TCPP, and TPPO in the entire region $(P<0.05, n=61)$. This was also observed for the Yellow Sea $(P<0.05, n=26)$ and the East China Sea $(P<0.05, n=20)$. Meanwhile, the bottom water exhibited a higher salinity $(32.6 \%$ ) than that of the surface water $(32.2 \%$ ) in the whole region $(P<0.01)$, which was also the case for the Yellow Sea (surface: $31.6 \%$ v.s. bottom: $32.0 \%$; $P<0.01$ ) and the East China Sea (surface: $33.4 \%$ v.s. bottom: $34.0 \%$; $P<0.01$ ) (Fig. S2). Vertically, the OPE concentrations were negatively correlated with salinity, which indicates that the vertical distribution of the seven OPEs could mainly be attributed to riverine inputs into the surface water and the dilution effect of high- salinity open ocean water in the bottom layers (Zhong et al., 2017). This argument was partially verified by the huge differences in the $\Sigma$ OPE concentrations and salinity between the surface water and the bottom water at site E7, which is located in the central region of the CDW (Figs. 1 and 2). The origin of the CDW is the Changjiang River, which is the largest river draining into the East China Sea and has been found to be characterized by high pollutant concentrations and low salinity (Kwon et al., 2018). The relatively high ¿OPE concentration $\left(55.7 \mathrm{ng} \mathrm{L}^{-1}\right)$ in association with a low salinity $(29.4 \%$, which was the lowest in the East China Sea) of the surface water, and the relatively low $\Sigma O P E$ concentration (26.5 $\mathrm{ng} \mathrm{L}^{-1}$ ) in association with a high salinity (32.7\%o) in the bottom water at $\mathrm{E} 7$ site might have been due to the influence of the CDW. This is a typical example that show the dominant effects of riverine inputs on the vertical distribution of OPEs.

Atmosphere deposition could be another factor affecting the vertical distribution patterns of OPEs. Li et al. (2018) estimated the annual atmospheric dry deposition of OPEs into the Bohai and Yellow Seas to be $12 \mathrm{t}$. The authors found that TCPP was the most abundant compounds, followed by TCEP, TiBP and TnBP. This input is comparable to the riverine inputs estimated by Wang et al. (2015). Thus, the OPE flux from the atmosphere may have been a significant additional source 
Table 1

Summary of OPE concentrations in the Bohai Sea (BS), Yellow Sea (YS), and East China Sea (ECS).

\begin{tabular}{|c|c|c|c|c|c|c|c|c|c|}
\hline \multirow[t]{2}{*}{ Regions } & \multirow[t]{2}{*}{ Values } & \multicolumn{8}{|l|}{ OPEs } \\
\hline & & $\mathrm{TiBP}$ & $\mathrm{T} n \mathrm{BP}$ & TCEP & ТCPP & TDCPP & $\mathrm{TPhP}$ & ТРPO & $\Sigma O P E s$ \\
\hline \multirow{3}{*}{ BS } & GMs (ng L ${ }^{-1}$ ) & 6.96 & $<\mathrm{MDL}$ & 9.56 & 11.4 & 2.03 & 0.15 & 5.16 & 39.1 \\
\hline & $\operatorname{Max} .\left(\operatorname{ng~L}^{-1}\right)$ & 27.4 & 37.2 & 19.8 & 26.7 & 5.16 & 3.28 & 26.6 & 100 \\
\hline & Min. (ng L $\left.\mathrm{L}^{-1}\right)$ & 1.97 & $<\mathrm{MDL}$ & 6.06 & 3.97 & $<\mathrm{MDL}$ & $<\mathrm{MDL}$ & 1.86 & 19.7 \\
\hline \multirow{3}{*}{ YS } & GMs (ng L ${ }^{-1}$ ) & $<\mathrm{MDL}$ & $<\mathrm{MDL}$ & 5.84 & 13.1 & 2.07 & 0.14 & 6.93 & 30.7 \\
\hline & $\operatorname{Max}\left(\operatorname{ng~L}^{-1}\right)$ & 9.64 & 26.5 & 16.9 & 35.6 & 8.13 & 0.76 & 43.5 & 86.8 \\
\hline & Min. (ng L $\left.{ }^{-1}\right)$ & $<\mathrm{MDL}$ & $<\mathrm{MDL}$ & 1.24 & 5.17 & $<\mathrm{MDL}$ & $<\mathrm{MDL}$ & 1.18 & 9.26 \\
\hline \multirow{3}{*}{ ECS } & GMs (ng L $\left.{ }^{-1}\right)$ & $<\mathrm{MDL}$ & $<\mathrm{MDL}$ & 1.93 & 9.63 & 0.51 & 0.11 & 1.63 & 15.1 \\
\hline & $\operatorname{Max} .\left(\operatorname{ng~L}^{-1}\right)$ & $<\mathrm{MDL}$ & $<\mathrm{MDL}$ & 12.4 & 29.6 & 4.92 & 1.95 & 19.1 & 55.7 \\
\hline & $\operatorname{Min} .\left(\mathrm{ng} \mathrm{L}^{-1}\right)$ & $<\mathrm{MDL}$ & $<\mathrm{MDL}$ & 0.59 & 5.61 & $<\mathrm{MDL}$ & $<\mathrm{MDL}$ & $<\mathrm{MDL}$ & 8.81 \\
\hline \multirow{3}{*}{ Sum } & GMs (ng L $\left.{ }^{-1}\right)$ & 0.166 & $<\mathrm{MDL}$ & 4.04 & 11.3 & 1.16 & 0.13 & 3.64 & 24.0 \\
\hline & $\operatorname{Max} .\left(\operatorname{ng~L}^{-1}\right)$ & 27.4 & 37.2 & 19.8 & 35.6 & 8.13 & 3.28 & 43.5 & 100 \\
\hline & $\operatorname{Min} .\left(n g \mathrm{~L}^{-1}\right)$ & $<\mathrm{MDL}$ & $<\mathrm{MDL}$ & 0.59 & 3.97 & $<\mathrm{MDL}$ & $<\mathrm{MDL}$ & $<\mathrm{MDL}$ & 8.81 \\
\hline
\end{tabular}

that resulted in high OPE concentrations in the surface water. However, although the Bohai Sea also presented a higher salinity in the bottom water than that in the surface water $(P<0.01)$, the OPE concentrations in the bottom water were not significantly lower than those of the surface water $(P>0.05)$. This phenomenon could be attributed to more pollution sources in the Bohai Sea, e.g., pollutant discharge zones and marine landfill (Zhong et al., 2018), which might act as additional sources for bottom water. Meanwhile, the shallow water depth (with an average depth of $18 \mathrm{~m}$ ) of the Bohai Sea is prone to be well-mixed by big wave in winter, and might also disturb the vertical distribution patterns of salinity and OPE concentrations.

In addition, the temperature difference between the surface water and bottom water was also considered. The surface water only showed a higher average temperature $\left(13.8^{\circ} \mathrm{C}\right)$ than that of the bottom water $\left(11.9{ }^{\circ} \mathrm{C}\right)$ in the Yellow Sea $(P<0.05, n=26)$, which indicates that the relationship between the OPE concentrations and temperature was not as obvious as that of salinity. The significance of the surfacebottom water temperature difference may be attributed to the Yellow Sea Cold Water Mass (YSCWM), which resides in the bottom of the Yellow Sea and is characterized by lower temperatures during the summer (Wei et al., 2016). According to Zhong et al. (2017), the YSCWM could induce a water stratification effect, thereby hindering the vertical exchange of the OPEs during the summer. Although this water mass begins to decline in the late autumn, it might still to some extent influence the vertical distribution of OPEs during the winter to some extent.

Further, with an aim of investigating the vertical distribution of the seven OPEs in detail, additional sea water samples from different layers (surface, subsurface, middle, sub-bottom, and bottom) were collected at sites S9, S13, E14, and E18. As shown in Fig. 3, the concentrations of $\Sigma$ OPEs and main individual OPEs (TCEP, TCPP, and TPPO) decreased with the increasing water depth before increasing again in the subbottom and/or bottom layers at all four sites. The decrease in the OPE concentrations from the surface to the middle layers could be attributed to more OPE sources (e.g., riverine inputs and atmospheric deposition) in the surface water (Zhong et al., 2017), whereas the rebounded in the concentrations below the middle layer can be attributed to an exchange between the sediment and bottom water. According to Zhong et al. (2018), sediment represents a reservoir of OPEs and might be a potential source to upper layer sea water. Moreover, OPEs residing in the

Table 2

Summary of OPE inventories for the BS, YS, and ECS.

\begin{tabular}{lllllllll}
\hline \multirow{2}{*}{ Regions } & \multicolumn{7}{l}{ Inventories of OPEs (ton) } \\
\cline { 2 - 8 } & TiBP & TnBP & TCEP & TCPP & TDCPP & TPhP & TPPO & ¿OPEs \\
\hline BS & 9.65 & - & 13.3 & 15.8 & 2.81 & 0.208 & 7.15 & 54.2 \\
YS & - & - & 97.6 & 219 & 34.6 & 2.34 & 116 & 513 \\
ECS & - & - & 505 & 2521 & 134 & 28.9 & 427 & 3953 \\
\hline
\end{tabular}

bottom and sub-bottom water could hardly diffuse into the upper layers due to thermoclines, as shown in Fig. 3, which usually formed below the middle layers. Thermoclines act as barriers to the vertical movement of the water and thus also for the OPEs dissolved within it, which could also have contributed to the rebound in the OPE concentrations in the sub-bottom and/or bottom water.

\subsection{Seasonal variation of the OPEs in the Bohai Sea and the Yellow Sea}

Seasonal variations have been observed for several pollutants, such as polycyclic aromatic hydrocarbons (PAH) (Ya et al., 2017), acidvolatile sulfide (Li et al., 2016), and organophosphorus pesticide (Mamta et al., 2015). Herein, based on the OPE concentrations reported by Zhong et al. (2017) and the data presented in the current study, we examined the seasonal variation (summer 2015 v.s. winter 2016) of OPE concentrations in the Bohai Sea and the Yellow Sea. During the summer of 2015, the GM concentrations of the $\Sigma$ OPEs (also TCEP, TCPP, TDCPP, TnBP, TiBP, TPhP, and TPPO, i.e., the same as the present study) in the Bohai Sea and the Yellow Sea were 33.4 and $21.0 \mathrm{ng} \mathrm{L}^{-1}$, respectively, whereas those during the winter of 2016 were 39.1 and $30.7 \mathrm{ng} \mathrm{L}^{-1}$, respectively. The seasonal variation in the $\Sigma O P E$ concentrations was assessed using a one-way ANOVA, which revealed that there was only a significant difference between the data for the summer of 2015 and winter of 2016 for the Yellow Sea $(P<0.01)$. The main individual OPE concentrations (i.e., TCEP, TCPP, and TPPO) also showed a similar seasonal variations as that showed by $\Sigma$ OPE concentration, although TCEP was an exception becausee the TCEP concentration during the summer was not significantly lower than that during the winter in the Yellow Sea. According to Ya et al. (2017), the seasonal variation in organic pollutants may be primarily attributed to the combined effects of multiple hydrological, meteorological, and biological factors, e.g., dilution by open-ocean water, surface runoff (mainly riverine inputs), atmospheric deposition, and biotic/abiotic enrichment and/or degradation.

A one-way ANOVA was also used to compare the salinity between the summer of 2015 and winter of 2016 to elucidate whether the seasonal variation in the OPEs was influenced by the dilution effects of the YSWM. YSWM is a branched of the Kuroshio Current and is characterized by a relatively high salinity and low pollutant concentrations (Lian et al., 2016). However, the results showed that there was no statistical significance between the salinity in the two seasons, and the GM salinity in summer $(31.0 \%$ o) was even lower than that in the winter (31.8\%). This implies that the dilution effects of open-ocean highsalinity seawater brought by the YSWM was not the dominant influencing factors for the OPE seasonal variation. Based on these results, we propose that riverine inputs and atmosphere deposition could have been among the main factors influencing the seasonal variation of the OPEs; however, no detailed data regarding the seasonal variation in 


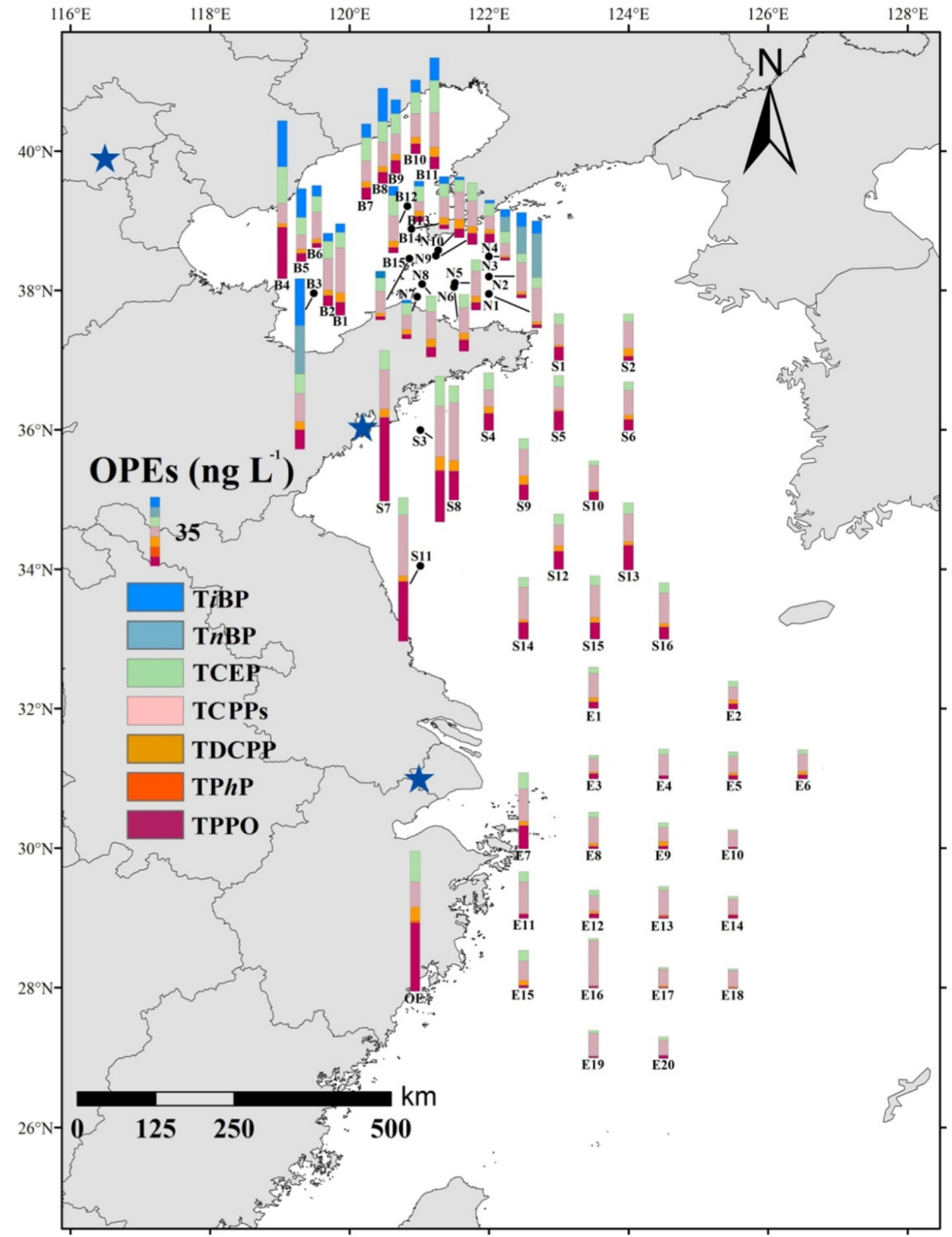

Fig. 2. Concentrations (average values of each layer at every site) and distribution patterns of the OPEs in the BS, YS, and ECS. OE: Oujiang estuary.

the rivers draining into the Yellow Sea or the atmospheric inputs to the Yellow Sea have been reported to date.

Interestingly, although TiBP and TnBP were not the main OPE pollutants in this area, they did show obvious seasonal variations. During the summer in the Bohai Sea, TiBP was only detected at a few sites with a fairly low GM concentration of $0.45 \mathrm{ng} \mathrm{L}^{-1}$, whereas TiBP was ubiquitously detected during the winter with a GM concentration of $6.96 \mathrm{ng} \mathrm{L}^{-1}$. Similarly, in the Bohai Sea and the Yellow Sea, TnBP was undetectable during the summer; however, it was detected at several sites
(B3, N1, N2, and N3) during the winter. The obvious seasonal variations for these two alkyl OPEs may be attributed to the photolysis and biodegradation of non-halogenated OPEs (Regnery and Puttmann, 2010), and/ or the additional large emissions related to their recent usage. Regnery and Puttmann (2010) found that non-halogenated OPEs were liable to be degraded in the presence of light and microorganism. The alkyl OPEs (TiBP and TnBP) would have received less sunlight during the winter and would have also experienced relatively lower microorganism degradation due to the lower temperatures in comparison with that in 

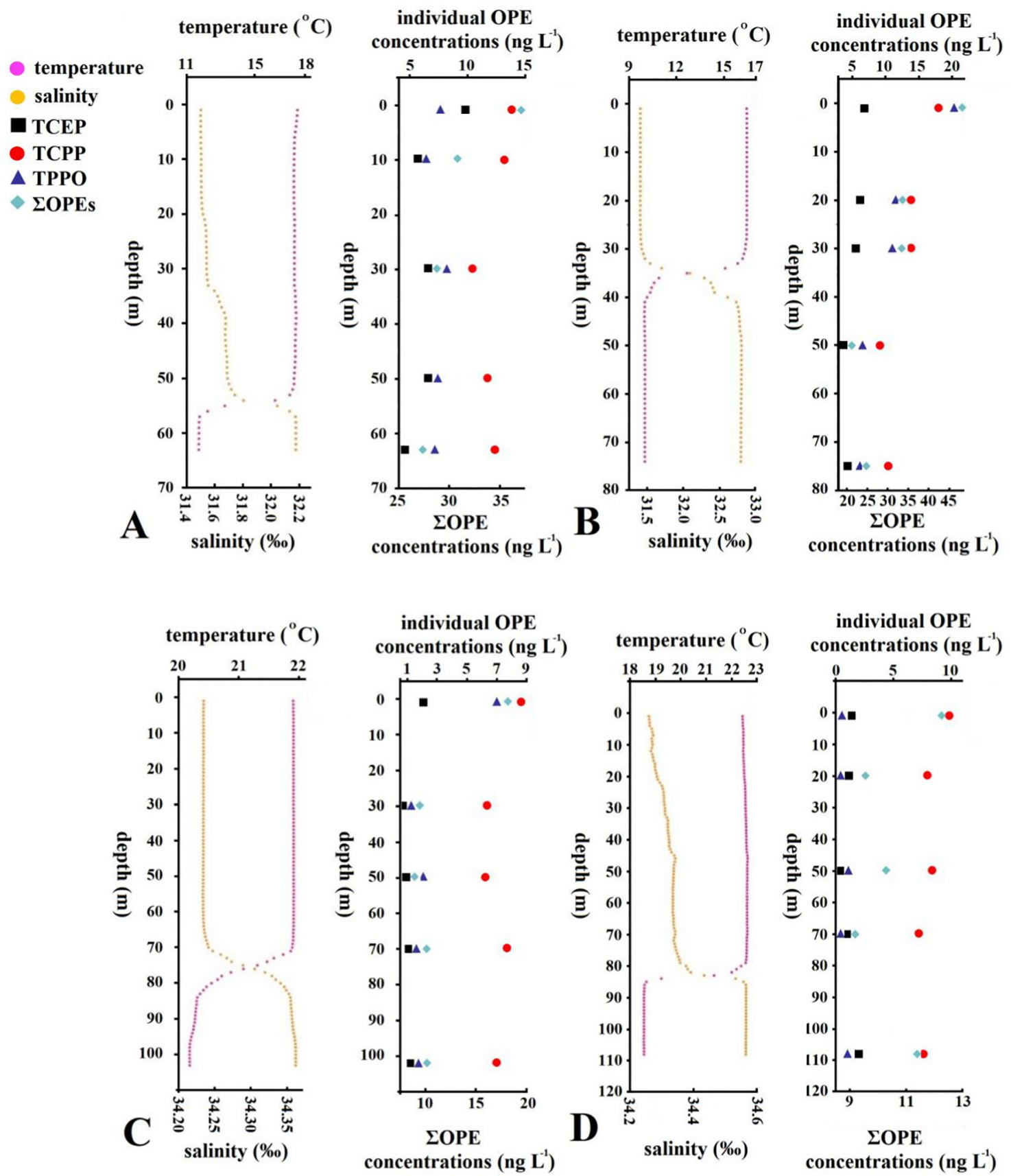

Fig. 3. Vertical distributions of the total OPEs (LOPEs) and the individual OPEs at sites S9 (A), S13 (B), E14 (C), and E18 (D).

summer. In the Bohai Sea and Yellow in our study, TiBP and TnBP may have been subjected to alleviated photolysis and biodegradation effects, thereby resulting in the higher concentrations in winter than those in summer. On the N1- N4 transect (from Shandong Province to Liaoning Province), the TnBP concentration exhibited an obvious declining trend and $\mathrm{T} n \mathrm{BP}$ was undetectable at site N4. This pattern might indicate that there were limited sources of TnBP in Shandong Province. Overall, the seasonal variations of TiBP and TnBP reflect the combined effects of photolysis, biodegradation and pollution sources.

\section{Conclusion}

This study analyzed the concentrations, distributions, and inventories of seven OPEs in the Bohai Sea, the Yellow Sea, and the East China Sea. Seasonal variations of the OPEs in the Bohai Sea and the Yellow Sea were compared. Relatively high concentrations of halogenated
OPEs (TCEP and TCPP) were observed, although TPPO was the main OPE pollutant. The highest $\Sigma$ OPE concentrations was found in the Bohai Sea, followed by the Yellow Sea and East China Sea. Ocean currents and riverine inputs could be among the main factors that influencing the horizontal distribution of the OPEs, whereas riverine inputs and atmospheric deposition together with water stratification may influence the vertical distribution of the OPEs in the study area. Inventory calculations suggested that the seven OPEs dissolved in seawater only accounted for small proportion in comparison with the amounts used. With respected to seasonal variations of the seven OPEs, relatively higher concentrations were determined during the winter that those in the summer in the Bohai Sea and the Yellow Sea. The data obtained in the present study shed light on the concentrations and distributions of OPEs in the marginal seas of China, especially in the East China Sea, and can help us to better monitor the pollution status of the OPEs. The high concentrations of the OPEs found in some coastal regions during 
this study, along with the extensively reported toxicities of OPEs to organisms and humans, highlight that more attention should be given to the alleviation of OPE pollution.

\section{CRediT authorship contribution statement}

Mingyu Zhong:Investigation, Methodology, Software, Writing - original draft.Jianhui Tang:Conceptualization, Supervision, Writing review \& editing, Data curation, Funding acquisition.Xinyu Guo:Visualization, Software, Validation.Chao Guo:Investigation, Writing - review \& editing.Fei Li:Writing - review \& editing.Huifeng Wu:Writing - review \& editing, Supervision, Resources.

\section{Declaration of competing interest}

No conflict of interest exits in the submission of this manuscript. The manuscript is approved by all authors for publication. I would like to declare on behalf of my co-authors that the work described was original research that has not been published previously, and not under consideration for publication elsewhere, in whole or in part. All the authors listed have approved the manuscript that is enclosed.

\section{Acknowledgement}

This study was supported by the National Natural Science Foundation of China (No. 41773138 and U1806207), and by the project of Yantai Institute of Coastal Zone Research, Chinese Academy of Sciences (No. YIC Y855011024). Hydrological data were courtesy by Dr. Z.Y. Wang from the Institute of Oceanology, Chinese Academy of Sciences, and are sincerely acknowledged. Special thanks to the crew of $R / V$ ' $B E I D O U$ ' for their generous helps.

\section{Appendix A. Supplementary data}

Supplementary data to this article can be found online at https://doi. org/10.1016/j.scitotenv.2020.140434.

\section{References}

Ali, N., Dirtu, A.C., Van den Eede, N., Goosey, E., Harrad, S., Neels, H., 't Mannetje, A., Coakley, J., Douwes, J., Covaci, A., 2012. Occurrence of alternative flame retardants in indoor dust from New Zealand: indoor sources and human exposure assessment. Chemosphere 88, 1276-1282.

Cao, D.D., Guo, J.H., Wang, Y.W., Li, Z.N., Liang, K., Corcoran, M.B., Hosseini, S., Bonina, S.M.C., Rockne, K.J., Sturchio, N.C., Giesy, J.P., Liu, J.F., Li, A., Jiang, G.B., 2017. Organophosphate esters in sediment of the Great Lakes. Environmental Science \& Technology 51, 1441-1449.

Chen, D., Letcher, R.J., Chu, S.G., 2012. Determination of non-halogenated, chlorinated and brominated organophosphate flame retardants in herring gull eggs based on liquid chromatography-tandem quadrupole mass spectrometry. J. Chromatogr. A 1220 169-174.

Fromme, H., Lahrz, T., Kraft, M., Fembacher, L., Mach, C., Dietrich, S., Burkardt, R., Volkel, W., Goen, T., 2014. Organophosphate flame retardants and plasticizers in the air and dust in German daycare centers and human biomonitoring in visiting children (LUPE 3). Environ. Int. 71, 158-163.

Greaves, A.K., Letcher, R.J., 2017. A review of organophosphate esters in the environment from biological effects to distribution and fate. Bull. Environ. Contam. Toxicol. 98, 2-7.

Hao, C.Y., Helm, P.A., Morse, D., Reiner, E.J., 2018. Liquid chromatography-tandem mass spectrometry direct injection analysis of organophosphorus flame retardants in Ontario surface water and wastewater effluent. Chemosphere 191, 288-295.

Hu, L.M., Lin, T., Shi, X.F., Yang, Z.S., Wang, H.J., Zhang, G., Guo, Z.G., 2011. The role of shelf mud depositional process and large river inputs on the fate of organochlorine pesticides in sediments of the Yellow and East China seas. Geophys. Res. Lett. 38

Hu, M.Y., Li, J., Zhang, B.B., Cui, Q.L., Wei, S., Yu, H.X., 2014. Regional distribution of halogenated organophosphate flame retardants in seawater samples from three coastal cities in China. Mar. Pollut. Bull. 86, 569-574.

Kwon, H.K., Kim, G., Hwang, J., Lim, W.A., Park, J.W., Kim, T., 2018. Significant and conservative long-range transport of dissolved organic nutrients in the Changjiang Diluted Water. Sci. Rep. 8 (1), 12768-12773.

Li, D.L., Liu, X.B., Liu, Z.G., Zhao, X.G., 2016. Spatial and seasonal variability of Total organic carbon and acid-volatile sulfide in surface sediments from the coastal water near Luan River Estuary-Dapu River Estuary, China. 2016 International Conference on Environmental Science and Engineering (Ese 2016), pp. 410-415.
Li, J., Xie, Z.Y., Mi, W.Y., Lai, S.C., Tian, C.G., Emeis, K.C., Ebinghaus, R., 2017. Organophosphate esters in air, snow, and seawater in the North Atlantic and the Arctic. Environmental Science \& Technology 51, 6887-6896.

Li, J., Tang, J.H., Mi, W.Y., Tian, C.G., Emeis, K.C., Ebinghaus, R., 2018. Spatial distribution and seasonal variation of organophosphate esters in air above the Bohai and Yellow Seas, China. Environmental Science \& Technology 52, 89-97.

Li, J., Wang, J., Cryder, Z., Taylor, A.R., Gan, J., 2019. Inference of organophosphate ester emission history from marine sediment cores impacted by wastewater effluents. Environmental Science \& Technology 53, 8767-8775.

Lian, E., Yang, S., Wu, H., Yang, C., Liu, J.T., 2016. Kuroshio subsurface water feeds the wintertime Taiwan warm current on the inner East China Sea shelf. Journal of Geophysical Research: Oceans 121 (7).

Liu, J.P., Xu, K.H., Li, A.C., Milliman, J.D., Velozzi, D.M., Xiao, S.B., Yang, Z.S., 2007. Flux and fate of Yangtze river sediment delivered to the East China Sea. Geomorphology 85, 208-224.

Liu, Y.E., Huang, L.Q., Luo, X.J., Tan, X.X., Huang, C.C., Corella, P.Z., Mai, B.X., 2018. Determination of organophosphorus flame retardants in fish by freezing-lipid precipitation, solid-phase extraction and gas chromatography-mass spectrometry. J. Chromatogr. A $1532,68-73$.

Ma, M., Feng, Z., Guan, C., Ma, Y., Xu, H., Li, H., 2001. DDT, PAH and PCB in sediments from the intertidal zone of the Bohai Sea and the Yellow Sea. Mar. Pollut. Bull. 42, 132-136.

Ma, Y.Q., Cui, K.Y., Zeng, F., Wen, J.X., Liu, H., Zhu, F., Ouyang, G.F., Luan, T.G., Zeng, Z.X., 2013. Microwave-assisted extraction combined with gel permeation chromatography and silica gel cleanup followed by gas chromatography-mass spectrometry for the determination of organophosphorus flame retardants and plasticizers in biological samples. Anal. Chim. Acta 786, 47-53.

Ma, Y.X., Xie, Z.Y., Lohmann, R., Mi, W.Y., Gao, G.P., 2017. Organophosphate ester flame retardants and plasticizers in ocean sediments from the North Pacific to the Arctic Ocean. Environmental Science \& Technology 51, 3809-3815.

Mamta, Rao, R.J., Wani, K.A., 2015. Monitoring of organochlorine and organophosphorus pesticide residues in water during different seasons of Tighra reservoir Gwalior, Madhya Pradesh, India. Environ. Monit. Assess. 187.

Marklund, A., Andersson, B., Haglund, P., 2003. Screening of organophosphorus compounds and their distribution in various indoor environments. Chemosphere 53 1137-1146.

Mihajlovic, I., Miloradov, M.V., Fries, E., 2011. Application of Twisselmann extraction, SPME, and GC-MS to assess input sources for organophosphate esters into soil. Environmental Science \& Technology 45, 2264-2269.

Moller, A., Sturm, R., Xie, Z.Y., Cai, M.H., He, J.F., Ebinghaus, R., 2012. Organophosphorus flame retardants and plasticizers in airborne particles over the northern Pacific and Indian Ocean toward the polar regions: evidence for global occurrence. Environmental Science \& Technology 46, 3127-3134.

Niu, Z., Zhang, Z., Li, J., He, J.H., Zhang, Y., 2019. Threats of organophosphate esters (OPEs) in surface water to ecological system in Haihe River of China based on species sensitivity distribution model and assessment factor model. Environ. Sci. Pollut. Res. 26, $10854-10866$

Ou, Y.X., 2011. Developments of organic phosphorus flame retardant industry in China. Chem Indust Eng Prog 30, 210-215.

Pang, L., Yang, H., Pang, R., Zhou, Y., Wang, Z., 2019. Occurrence, distribution, and risk assessment of organophosphate esters in urban street dust in the central province of Henan, China. Environ. Sci. Pollut. Res. 26 (27).

Reemtsma, T., Quintana, J.B., Rodil, R., Garcia-Lopez, M., Rodriguez, I., 2008. Organophosphorus flame retardants and plasticizers in water and air I. Occurrence and fate. TracTrends In Analytical Chemistry 27, 727-737.

Regnery, J., Puttmann, W., 2010. Occurrence and fate of organophosphorus flame retardants and plasticizers in urban and remote surface waters in Germany. Water Res. 44, 4097-4104.

Rodil, R., Quintana, J.B., Reemtsma, T., 2005. Liquid chromatography-tandem mass spectrometry determination of nonionic organophosphorus flame retardants and plasticizers in wastewater samples. Anal. Chem. 77, 3083-3089.

Shen, Y.L., Lv, X.Q., Wang, C.H., 2013. Estimation of pollutant discharge in the Bohai Sea with variational assimilation method. Proceedings of the 2013 the International Conference on Remote Sensing, Environment and Transportation Engineering (Rsete 2013). 31, pp. 725-728.

Staaf, T., Ostman, C., 2005. Organophosphate triesters in indoor environments. J. Environ. Monit. 7, 883-887.

Stapleton, H.M., Klosterhaus, S., Eagle, S., Fuh, J., Meeker, J.D., Blum, A., Webster, T.F., 2009 Detection of organophosphate flame retardants in furniture foam and US house dust. Environmental Science \& Technology 43, 7490-7495.

Sühring, R., Diamond, M.L., Scheringer, M., Wong, F., Pućko, M., Stern, G., Burt, A., Hung, H. Fellin, P., Li, H., Jantunen, L.M., 2016. Organophosphate esters in Canadian Arctic air: occurrence, levels and trends. Environmental Science \& Technology 50, 7409-7415.

van der Veen, I., de Boer, J., 2012. Phosphorus flame retardants: properties, production, environmental occurrence, toxicity and analysis. Chemosphere 88, 1119-1153.

Wang, R.M., Tang, J.H., Xie, Z.Y., Mi, W.Y., Chen, Y.J., Wolschke, H., Tian, C.G., Pan, X.H., Luo, Y.M., Ebinghaus, R., 2015. Occurrence and spatial distribution of organophosphate ester flame retardants and plasticizers in 40 rivers draining into the Bohai Sea, north China. Environ. Pollut. 198, 172-178.

Wang, Y., Wu, X.W., Zhang, Q.N., Hou, M.M., Zhao, H.X., Xie, Q., Du, J., Chen, J.W., 2017. Organophosphate esters in sediment cores from coastal Laizhou Bay of the Bohai Sea, China. Sci. Total Environ. 607, 103-108.

Wei, Q.S., Yu, Z.G., Wang, B.D., Fu, M.Z., Xia, C.S., Liu, L., Ge, R.F., Wang, H.W., Zhan, R., 2016 Coupling of the spatial-temporal distributions of nutrients and physical conditions in the southern Yellow Sea. J. Mar. Syst. 156, 30-45.

Ya, M.L., Wang, X.H., Wu, Y.L., Li, Y.Y., Yan, J.M., Fang, C., Zhao, Y.Y., Qian, R.R., Lin, X.L. 2017. Seasonal variation of Terrigenous polycyclic aromatic hydrocarbons along the 
marginal seas of China: input, phase partitioning, and ocean-current transport. Environmental Science \& Technology 51, 9072-9079.

Zhang, Y., 2014. Global market analysis of flame retardant. Fine and specialty Chemicals $22,20-24$.

Zhong, M., Tang, J., Mi, L., Li, F., Wang, R., Huang, G., Wu, H., 2017. Occurrence and spatial distribution of organophosphorus flame retardants and plasticizers in the Bohai and Yellow Seas, China. Mar. Pollut. Bull. 121, 331-338.
Zhong, M.Y., Wu, H.F., Mi, W.Y., Li, F., Ji, C.L., Ebinghaus, R., Tang, J.H., Xie, Z.Y., 2018. Occurrences and distribution characteristics of organophosphate ester flame retardants and plasticizers in the sediments of the Bohai and Yellow Seas, China. Sci. Total Environ. $615,1305-1311$. 